\title{
Discrete Modes of Life Cycle in Velarifictorus micado Species Complex (Orthoptera: Gryllidae)
}

\author{
Zhuqing He and Makio Takeda \\ Graduate School of Agricultural Science, Kobe University, 1-1 Rokko-Dai, Nada, Kobe, Hyogo 657-8501, Japan \\ Correspondence should be addressed to Makio Takeda; mtakeda@kobe-u.ac.jp
}

Received 27 October 2013; Accepted 19 November 2013

Academic Editors: Y. Abe and C. J. Bidau

Copyright ( 2013 Z. He and M. Takeda. This is an open access article distributed under the Creative Commons Attribution License, which permits unrestricted use, distribution, and reproduction in any medium, provided the original work is properly cited.

\begin{abstract}
Different modes of climatic adaptation often lead to a split in reproductive cohesion and stimulate speciation between populations with different patterns of life cycle. We here examined egg development and photoperiodic adaptations in the nymphal development of Velarifictorus micado. We defined fast hatching populations as nymphal diapause and slow hatching populations as egg diapause. The nymphs were reared under two photoperiods, LD 16:8 and LD 12:12 at $27.5^{\circ} \mathrm{C}$, and the mean days of nymphal development were compared. The results indicate that the nymphal diapause populations showed slower nymphal development under LD $12: 12$ than under LD $16: 8$, and this retardation increased with the increase of original latitude. The egg diapause populations showed slower nymphal development under LD 16:8 than under LD 12:12. These features help synchronizing their overwintering stages. Gene flow from the opposite forms may disturb this synchronization mechanism, and therefore natural selection should favor displacement of the two forms. This could be an incipient climatic isolation mechanism of reproductive stage.
\end{abstract}

\section{Introduction}

Crickets are omnivorous feeders widely distributed in low and wetland habitats between $57^{\circ}$ north and south latitudes [1]. Their life cycles can be divided into two basic types: one without seasonality and the other with it [2]. Crickets of the first type continue producing new generations throughout the year, so they lack synchrony of generations. Crickets of the second type usually have a unique and regular life cycle, where climate exerts synchronizing effects $[1,3]$. Crickets in temperate zones with different life cycle show different photoperiod responses. Masaki researched the photoperiodic response of Japanese crickets systematically [4-10] and he defined three types of photoperiodic response: long-day type, short-day type, and intermediate-day type [11] (other complex models also exist [12]). Crickets belonging to longday type develop fast and emerge synchronously under long photoperiod (LD 16:8, 16 hours day time and 8 hours night time, the same below) and they are bivoltine or multivoltine with nymph diapause, such as Teleogryllus emma (Ohmachi and Matsuura, 1951) and T. infernalis (Saussure, 1877) [10, $13,14]$. Crickets belonging to short-day type develop fast under short photoperiod (LD 12:12) and are univoltine with egg diapause, such as Modicogryllus siamensis Chopard, 1961 [5-7]. Intermediate-day type crickets include Dianemobius nigrofasciatus (Matsumura, 1904) and Polionemobius taprobanensis (Walker, 1869) in Japan. In warm area, they are bivoltine. These two species emerge quickly in both short and long photoperiods but emerge slowly under intermedium photoperiod (LD 14:10). The first generation emerges in summer and lays nondiapause eggs according to long photoperiod [15]. The second generation develops slowly under intermedium photoperiod in early autumn and emerges synchronously under short photoperiod [8]. But in northern Japan, the same species are univoltine and only produce diapause eggs as short-day type.

McNeill first noticed the two population of field crickets with different life cycle [16]. Alexander and Bigelow [17] proposed the model of allochronic speciation and separated G. veletis (Alexander and Bigelow, 1960) from Gryllus pennsylvanicus Burmeister, 1838. They were very similar in morphology and overlapped in some areas. They were treated as same species but had different life cycles. Sympatric divergence of life cycles resulted in seasonal isolation of their offspring. However, later molecular taxonomic works ruled out the relatedness of these two species $[18,19]$. Both of them 
have other sibling species with the similar life cycle. Their overlap seems to be the result of migration.

Velarifictorus micado (Saussure, 1877) develops two diapause strategies in Japan [3]. One population is strictly univoltine, which enters an obligatory diapause at egg stage as short-day type. Their calling songs can be heard from August to October. This population is distributed all over Japan, except the Hokkaido and the Ryukyu Islands. Another population, distributed in southern Japan, grows slowly and overwinters at a late nymphal stage. They are univoltine and their calling songs can be heard from May to July. Masaki concluded that this is a form of climatic speciation in which low winter temperatures induce populations to have to diapause at egg or nymphal stage [20]. Egg diapause populations were frequent in north area and nymph diapause populations were frequent in south area. Such selection will form two species after enough time [20].

Masaki cited V. micado as an instance for his hypothesis [20]. He pointed out that two diapause strategies could both succeed in northern colonization and had some overlaps. However, V. micado is not restricted to Japan but has a wide distribution in East Asia (Japan, Korea, China, Taiwan and Indo-China Peninsula) from Harbin, China, $\left(45.80^{\circ} \mathrm{N}\right.$, sometimes reaching $\left.-30^{\circ} \mathrm{C}\right)$ to Siem Reap, Cambodia $\left(13.37^{\circ} \mathrm{N}\right.$, a tropical area). Their life cycles in other Asian countries are not well understood. Because of its wide distribution and probably different climatic adaptations in different areas, $V$. micado offers a good subject for climatic adaptation study. There is a need for life cycle analysis of this species and Masaki's climatic speciation should be tested in a wider area. In this study, we analyzed egg and nymphal development to discuss its relevance to climatic speciation.

\section{Materials and Methods}

Seven geographic populations of $V$. micado were collected from China, Japan, Korea, Taiwan and Vietnam. Their offspring were reared for this study (see details in Table 1 and Figure 1). Gravid females were allowed to lay eggs for 24 hours. These eggs oviposited into soil were incubated at $27.5^{\circ} \mathrm{C}$. Hatching number was recorded everyday. Then, nymphs were reared in transparent plastic cups $(10 \mathrm{~cm}$ in diameter $\times 10 \mathrm{~cm}$ in height) with 10 individuals per cup under LD $16: 8$ or LD $12: 12$ at $27.5^{\circ} \mathrm{C}$ in a walk-in constant temperature room (NK SYSTEM Experimental Laboratory, LP$1 / 2 / 3 \mathrm{PH}$ ). They were fed with rodent food (MF, ORIENTAL YEAST Co. Ltd.) and water in cotton-plugged glass vials until nymphs reached adult stage. The nymphs were checked everyday. Adults were removed from the culture in order to prevent cannibalism.

\section{Results}

There were two types of egg hatching rate. Populations of Vietnam, S. China, Taiwan and Japan had relatively fast hatching rate. Their nymphs hatched in almost 20 days. They are defined as nymph diapause populations. Populations of M. China, N. China and Korea had relatively slow hatching

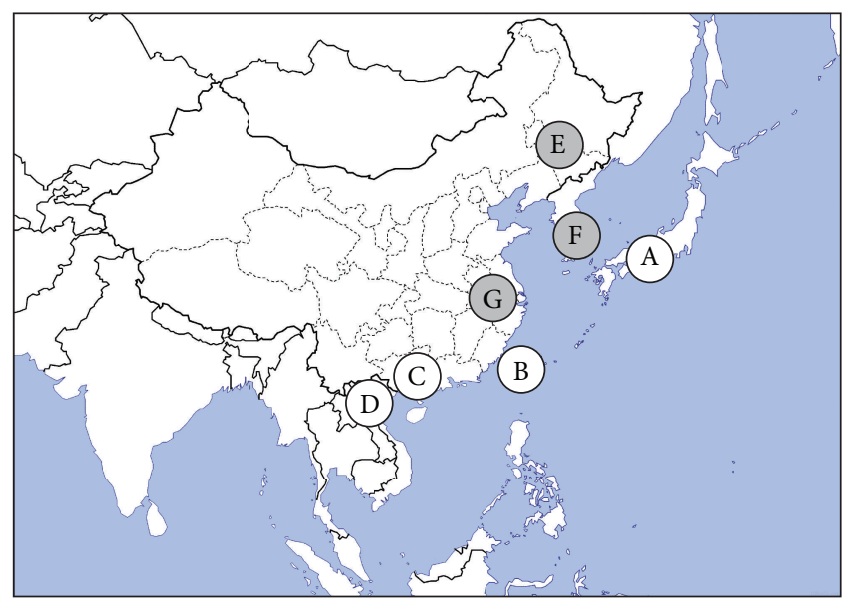

FIGURE 1: Geographic distribution of samples. Nymphal diapause: (A) Osaka, Japan; (B) Wulai, Taiwan; (C) Shenzhen, S. China; (D) Tam Dao, Vietnam. Egg diapause, (E) Changchun, N. China, (F) Daegu, Korea, (G) Tianmushan, M. China.

rate. The range of mean hatching days were from 40 to 78 days with large standard deviation, which mean they did not hatch synchronously. In the wild, eggs of these populations need low temperature to terminate diapause. If these eggs are directly incubated at high temperature, their hatching days will vary [5]. They are defined as egg diapause populations (Table 2).

The period of nymphal development was calculated and was compared between two photoperiods (Table 3, Figure 2). Results showed significant differences of nymphal developmental days under long and short photoperiod in all populations. In the egg diapause populations, individuals under LD 12:12 developed faster than those under LD 16:8, while those of nymphal diapause populations developed slower under LD 12:12 than under LD 16:8. Egg diapause populations developed faster and more synchronously. The mean developmental time of $\mathrm{M}$. China population was 74 days, the longest under LD 16:8, and N. China population finished it in 50 days. On the other hand, nymphal diapause populations spent less time at the egg stage, but more time at the nymphal stage under short photoperiod. They developed fast (about 60-80 days) under LD 16:8, but slow (over 90 days) under LD $12: 12$. The Japanese population of Osaka was an exception their emergence days varied from 50 to 150 days under both photoperiod regimes.

\section{Discussion}

Masaki investigated the life cycle of Japanese V. micado and defined these two populations with different life cycle as two species [3]. He concluded that this was a case of climatic speciation, comparable to the allochronic speciation model by Alexander and Bigelow [17]. As winter becomes more severe in northern Japan, V. micado must enter diapause at either egg or nymphal stage. Disruptive selection will make the individuals enter either diapause stage strictly. 
TABLE 1: Collection sites of populations.

\begin{tabular}{lcc}
\hline Population & Collection site & Latitude and longitude \\
\hline Japan & Osaka, Japan & $34.69^{\circ} \mathrm{N} 135.50^{\circ} \mathrm{E}$ \\
Taiwan & Wulai, Xinbei, Taiwan & $24.87^{\circ} \mathrm{N} 121.55^{\circ} \mathrm{E}$ \\
S. China & Shenzhen, Guangdong, China & $22.54^{\circ} \mathrm{N} 114.06^{\circ} \mathrm{E}$ \\
Vietnam & Tam Dao, Vietnam & $21.57^{\circ} \mathrm{N} 105.67^{\circ} \mathrm{E}$ \\
N. China & Changchun, Jilin, China & $43.90^{\circ} \mathrm{N} 125.33^{\circ} \mathrm{E}$ \\
Korea & Daegu, Korea & $35.97^{\circ} \mathrm{N} 128.60^{\circ} \mathrm{E}$ \\
M. China & Tianmushan, Zhejiang, China & $30.32^{\circ} \mathrm{N} 119.43^{\circ} \mathrm{E}$ \\
\hline
\end{tabular}

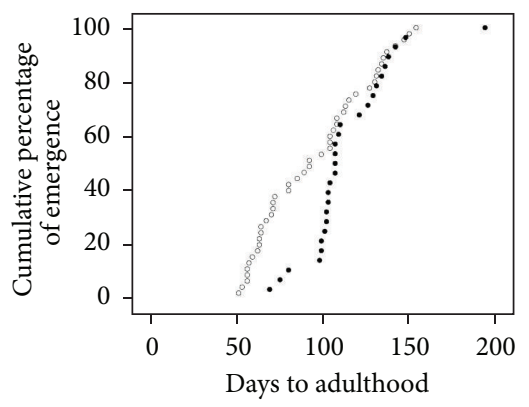

(a)

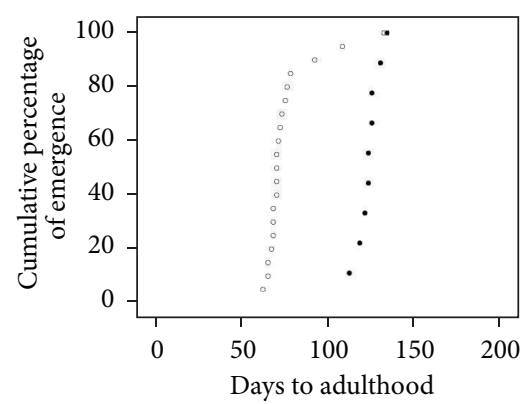

(b)

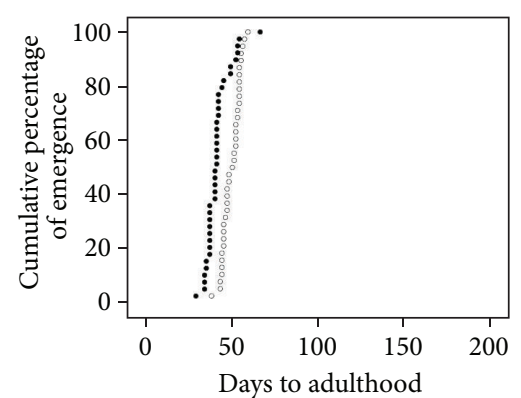

(e)

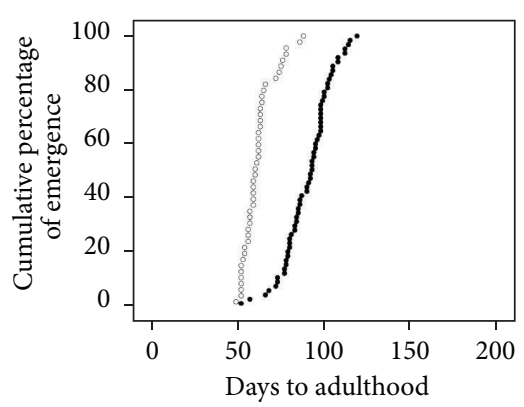

(c)

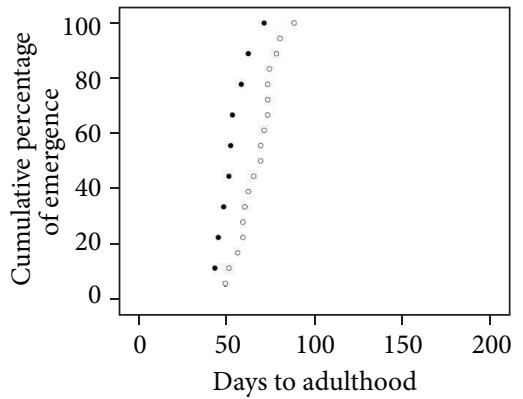

(f)

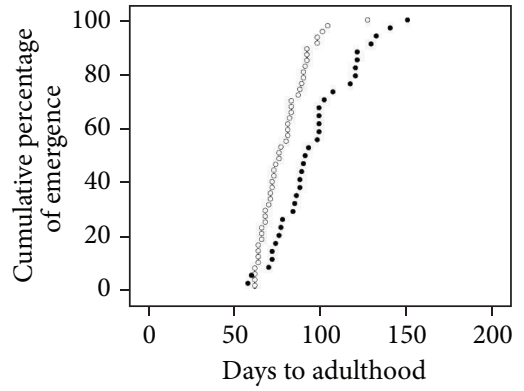

(d)

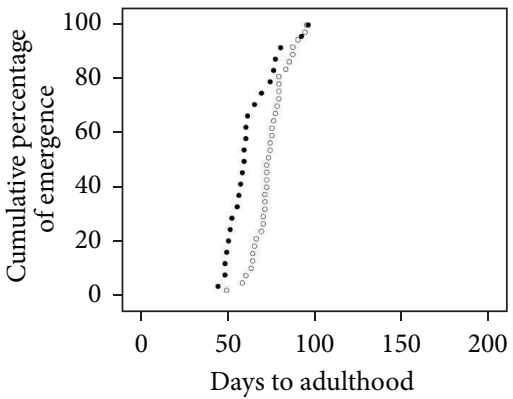

(g)

Figure 2: Cumulative percentage of V. micado emergence. Nymphal diapause: (a) Osaka, Japan; (b) Wulai, Taiwan; (c) Shenzhen, S. China; (d) Tam Dao, Vietnam. Egg diapause, (e) Changchun, N. China, (f) Daegu, Korea, (g) Tianmushan, M. China (circles, LD 16: 8; solid circles, LD $12: 12$ ).

We investigated seven populations of $V$. micado from Vietnam, China, Taiwan, Korea, and Japan. Fast egg developing populations developed slowly at nymphal stage and vice versa. Their life cycle can be deduced by these results because it is adjusted by photoperiodic response and thermal parameters for development [21]. The Vietnam population probably develops continuously, although developmental days under LD 12:12 showed slight retardation. They may overwinter mainly at nymphal stage because they face a shortage of food and cold temperature in winter. The nymphal development was less synchronous than those of other nymphal overwintering populations. Compared with the S. China and 
TABLE 2: Diapause stage and egg hatching days.

\begin{tabular}{lccc}
\hline Population & $N$ & Mean hatching days \pm SD & Diapause stage \\
\hline Japan & 251 & $17.68 \pm 1.28$ & nymph \\
Taiwan & 382 & $16.66 \pm 1.21$ & nymph \\
S. China & 447 & $16.27 \pm 1.26$ & nymph \\
Vietnam & 369 & $17.09 \pm 1.28$ & nymph \\
\hline N. China & 352 & $39.64 \pm 12.33$ & egg \\
Korea & 225 & $56.18 \pm 13.65$ & egg \\
M. China & 416 & $78.29 \pm 17.07$ & egg \\
\hline
\end{tabular}

TABLE 3: Durations of nymphal development under LD 12:12 and LD 16: 8.

\begin{tabular}{|c|c|c|c|c|c|c|}
\hline & LD & $N$ & Nymphal duration \pm SD & Retardation & \multicolumn{2}{|c|}{$t$-test } \\
\hline \multicolumn{7}{|c|}{ Nymphal diapause } \\
\hline \multirow{2}{*}{ Japan } & $12: 12$ & 28 & $113.61 \pm 25.06$ & \multirow{2}{*}{18.41} & \multirow{2}{*}{$t(66.5)=2.766$} & \multirow{2}{*}{$P=0.007$} \\
\hline & $16: 8$ & 45 & $95.20 \pm 31.36$ & & & \\
\hline \multirow{2}{*}{ Taiwan } & $12: 12$ & 9 & $124.44 \pm 6.39$ & \multirow{2}{*}{47.44} & \multirow{2}{*}{$t(27)=8.169$} & \multirow{2}{*}{$P<0.001$} \\
\hline & $16: 8$ & 20 & $77.00 \pm 16.74$ & & & \\
\hline \multirow{2}{*}{ S. China } & $12: 12$ & 63 & $90.67 \pm 13.72$ & \multirow{2}{*}{28.78} & \multirow{2}{*}{$t(105.5)=13.110$} & \multirow{2}{*}{$P<0.001$} \\
\hline & $16: 8$ & 45 & $61.89 \pm 9.08$ & & & \\
\hline \multirow{2}{*}{ Vietnam } & $12: 12$ & 34 & $96.59 \pm 22.71$ & \multirow{2}{*}{17.78} & \multirow{2}{*}{$t(50.3)=4.059$} & \multirow{2}{*}{$P<0.001$} \\
\hline & $16: 8$ & 47 & $78.81 \pm 13.75$ & & & \\
\hline \multicolumn{7}{|c|}{ Egg diapause } \\
\hline \multirow{2}{*}{ N. China } & $12: 12$ & 39 & $41.46 \pm 6.97$ & \multirow{2}{*}{-8.07} & \multirow{2}{*}{$t(75)=-5.861$} & \multirow{2}{*}{$P<0.001$} \\
\hline & $16: 8$ & 38 & $49.53 \pm 4.89$ & & & \\
\hline \multirow{2}{*}{ Korea } & $12: 12$ & 9 & $53.67 \pm 8.80$ & \multirow{2}{*}{-13.5} & \multirow{2}{*}{$t(25)=-3.348$} & \multirow{2}{*}{$P=0.003$} \\
\hline & $16: 8$ & 18 & $67.17 \pm 10.34$ & & & \\
\hline \multirow{2}{*}{ M. China } & $12: 12$ & 25 & $61.88 \pm 13.73$ & \multirow{2}{*}{-12.12} & \multirow{2}{*}{$t(60)=-3.868$} & \multirow{2}{*}{$P<0.001$} \\
\hline & $16: 8$ & 37 & $74.00 \pm 9.74$ & & & \\
\hline
\end{tabular}

Taiwan populations, the degree of retardation increased with latitude (47 days in Taiwan population, 29 days in the S. China population, and 18 days in the Vietnam populations), which suggests that these two populations spend more time under short photoperiod. If such natural selection has been acting for generations, it would be expected that both populations would emerge more synchronously. The developmental rates were fast under LD 16:8, which suggests they may reproduce continually as bivoltine or multivoltine if heat units are enough.

The variation of Osaka population emergency was large. This could be the result of two diapause termination mechanisms. Tanaka investigated Pteronemobius nitidus (Bolivar, 1901) and found it had a complex photoperiod response [12]. P. nitidus is a univoltine species that enters diapause at the nymphal stage in winter and emerges as adults the following summer. Their first diapause stage is terminated by the decrease of photoperiod in autumn and second diapause stage is terminated by the increase of photoperiod in summer. Under stationary photoperiod, this species developed less synchronously. Our result of Osaka population followed this complex photoperiod response model and suggests that this population is univoltine and overwinters at nymphal stage.

Three egg-diapause populations all emerged synchronously and fast. They are univoltine species and enter diapause at egg stage. The egg diapause of T. emma crickets has been studied by Masaki [5]. In his study, southern individuals of T. emma developed slowly and the developmental period was longer than that in northern individuals. If the southern individuals migrated to the north, their low growth rate would make them develop so slowly that they might remain at nymphal stage when winter came. On the other hand, if northern individuals migrated to the south, they might develop so fast that they would lay their eggs in early fall and eggs would hatch in wrong season. Our result is consistent with the above interpretation. Nymphal developmental days decreased with the increase of latitude under both photoperiods because the limiting warm season in the north forces them to develop fast. Egg diapause populations completely follow Masaki's model.

$V$. micado in tropical areas produced continuous generations. While in temperature areas, low temperature in winter became the biggest challenge. They should enter diapause to overwinter. Vietnam population developed slightly slowly under LD 12 : 12, which suggests incipient nymphal overwintering adaptation. This retardation increased with latitude reflecting longer time of winter season. The developmental rates of Taiwan and S. China populations were fast and synchronous under LD $16: 8$, but were slow under LD $12: 12$. These results indicate that several generations would have to 
pass before winter when enough heat units have accumulated. This diapause strategy does not fit in Osaka because the warm season is not long enough for two generations to be completed. The Osaka population has to enter diapause at nymphal stage strictly and become univoltine. This is probably the north border of the nymphal diapause population. In the egg diapause population, all populations are univoltine, which reflects their better adaptation in north area. This egg diapause strategy can be found in a wide range in North China and Japan (though we did not have the data of Japanese $V$. micado overwintering at egg stage). Although Masaki [20] suggested that speciation occurred in southern Japan, there is another possibility that speciation might have occurred in southern China. The egg diapause population could have migrated from Korea to Japan. They met the nymphal diapause population in Japan, which colonized from Taiwan and Ryukyu Islands. Because both of them should strictly enter diapause at either egg or nymphal stage, they hardly have chance to mate. If it happened, individuals with irregular life cycle will be rejected by natural selection. $T$. emma and T. occipitalis (Serville, 1838) and other examples of climatic speciation reported by Masaki were also distributed in China. Further study of cricket life cycle in the area between south and middle China will help us understand the transition from nymphal diapause to egg diapause better.

\section{Acknowledgments}

The authors thank Drs. Ma Libin, Hu Jiayao, and Zhang Tao for the collection of live populations from Changchun, Tianmushan, and Shenzhen, respectively. The foreign populations were reared in laboratory under a special quarantine permit (22-684, 23-207, 23-489, 24-450, 24-549, 24-617) from the Kobe Branch of the Plant Quarantine Service.

\section{References}

[1] F. Huber, T. E. Moore, and W. Loher, Cricket Behavior and Neurobiology, Cornell University Press, New York, NY, USA, 1989.

[2] R. D. Alexander, "Life cycle origins, speciation, and related phenomena in crickets," Quarterly Review of Biology, vol. 43, no. 1, pp. 1-41, 1968.

[3] S. Masaki and T. J. Walker, "Cricket life cycles," Evolutionary Biology, vol. 21, pp. 349-423, 1987.

[4] S. Masaki, "Geographic variation of diapause in insects," Bulletin of the Faculty of Agriculture Hirosaki University, vol. 7, pp. 66-98, 1961.

[5] S. Masaki, "Adaptation to local climatic conditions in the emma field cricket (Orthoptera: Gryllidae)," Japanese Journal of Entomology, vol. 31, pp. 249-260, 1963.

[6] S. Masaki, "Photoperiodism and geographic variation in the nymphal growth of Teleogryllus yezoemma (Ohmachi et Matsuura)(Orthoptera: Gryllidae)," Japanese Journal of Entomology, vol. 34, pp. 277-288, 1966.

[7] S. Masaki, "Geographic variation and climatic adaptation in a field cricket (Orthoptera: Gryllidae)," Evolution, vol. 21, no. 4, pp. 725-741, 1967.
[8] S. Masaki, "Climatic adaptation and photoperiodic response in the band legged ground cricket," Evolution, vol. 26, no. 4, pp. 587-600, 1972.

[9] S. Masaki and F. Ohmachi, "Divergence of photoperiodic response and hybrid development in Teleogryllus (Orthoptera: Gryllidae)," Japanese Journal of Entomology, vol. 35, pp. 83-105, 1967.

[10] S. Masaki and T. Sugahara, "Photoperiodic control of larval development and wing form in Modicogryllus sp. (Orthoptera: Gryllidae)," Ecological Research, vol. 7, no. 1, pp. 25-30, 1992.

[11] T. Kidokoro and S. Masaki, "Photoperiodic response in relation to variable voltinism in the ground cricket, Pteronemobius fascipes Walker (Orthoptera: Gryllidae)," Japanese Journal of Ecology, vol. 28, pp. 291-298, 1978.

[12] S. Tanaka, "Multiple Photoperiodic control of the seasonal life cycle in Pteronemobius nitidus Bolivar (Orthoptera: Gryllidae)," Japanese Journal of Entomology, vol. 47, pp. 465-475, 1979.

[13] N. Taniguchi and K. Tomioka, "Duration of development and number of nymphal instars are differentially regulated by photoperiod in the cricket Modicogryllus siamensis (Orthoptera: Gryllidae)," European Journal of Entomology, vol. 100, no. 2, pp. 275-281, 2003.

[14] S. Tanaka, T. Arai, and K. Tanaka, "Nymphal development, diapause and cold-hardiness in a nymph-overwintering cricket," Entomological Science, vol. 2, pp. 173-182, 1999.

[15] S. Shiga and H. Numata, "Effects of compound eye-removal on the photoperiodic response of the band-legged ground cricket, Pteronemobius nigrofasciatus," Journal of Comparative Physiology A, vol. 179, no. 5, pp. 625-633, 1996.

[16] J. McNeill, "Notes upon Gryllus and Oecanthus," Entomologica Americana, vol. 5, pp. 101-104, 1889.

[17] R. D. Alexander and R. S. Bigelow, "Allochronic speciation in field crickets, and a new species, Acheta veletis," Evolution, vol. 14, no. 3, pp. 334-346, 1960.

[18] R. G. Harrison and S. M. Bogdanowicz, "Mitochondrial DNA phylogeny of North American field crickets: perspectives on the evolution of life cycles, songs, and habitat associations," Journal of Evolutionary Biology, vol. 8, no. 2, pp. 209-232, 1995.

[19] Y. Huang, G. Ortí, M. Sutherlin, A. Duhachek, and A. Zera, "Phylogenetic relationships of North American field crickets inferred from mitochondrial DNA data," Molecular Phylogenetics and Evolution, vol. 17, no. 1, pp. 48-57, 2000.

[20] S. Masaki, "Climatic speciation in Japanese ground crickets," GeoJournal, vol. 7, no. 6, pp. 483-490, 1983.

[21] T. Arai, J. Liu, C. Huang, X. Cheng, Y. Watari, and M. Takeda, "Species specificity in photoperiodic control of nymphal development in four species of cricket from North-West China," Entomological Science, vol. 7, no. 3, pp. 237-244, 2004. 

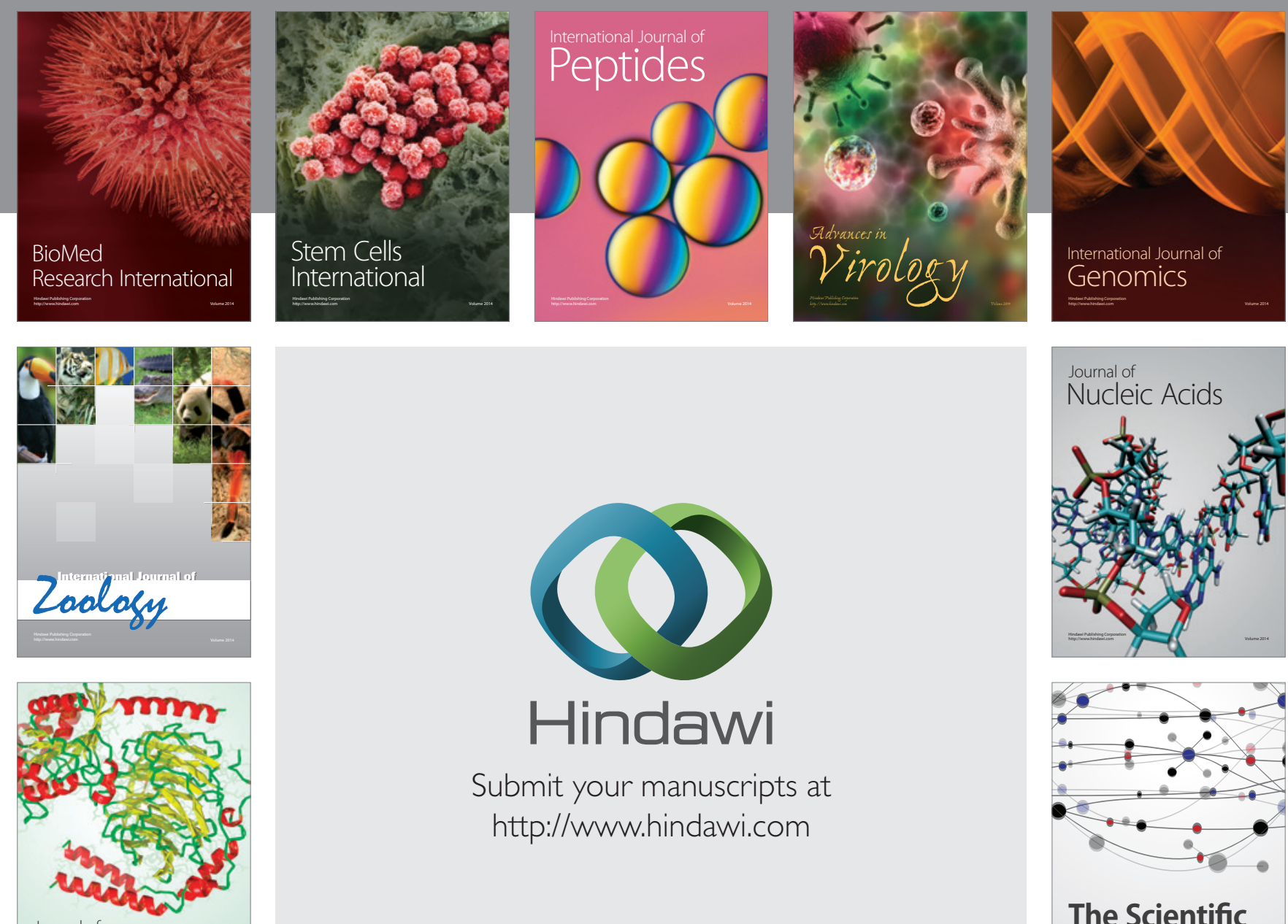

Submit your manuscripts at

http://www.hindawi.com

Journal of
Signal Transduction
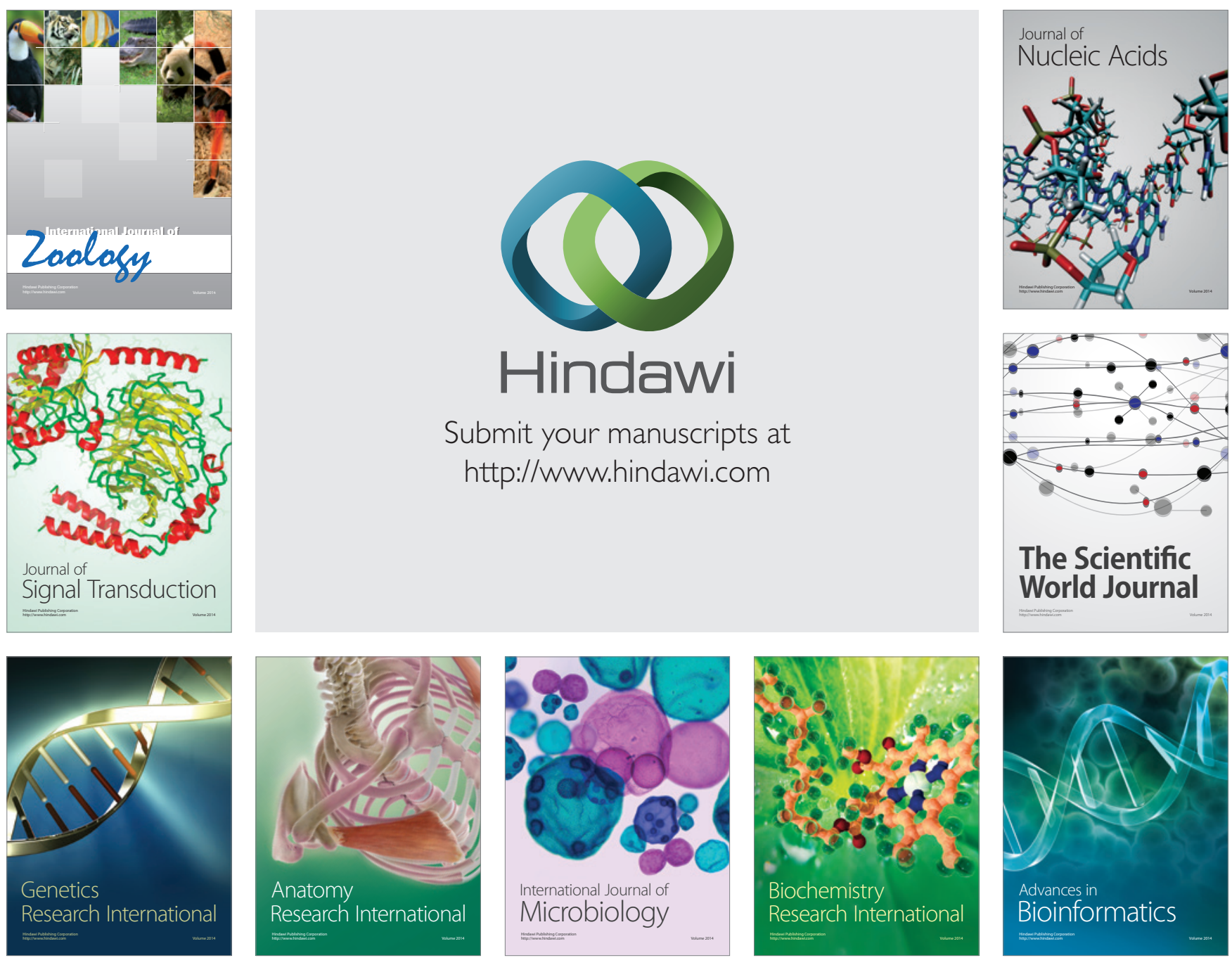

The Scientific World Journal
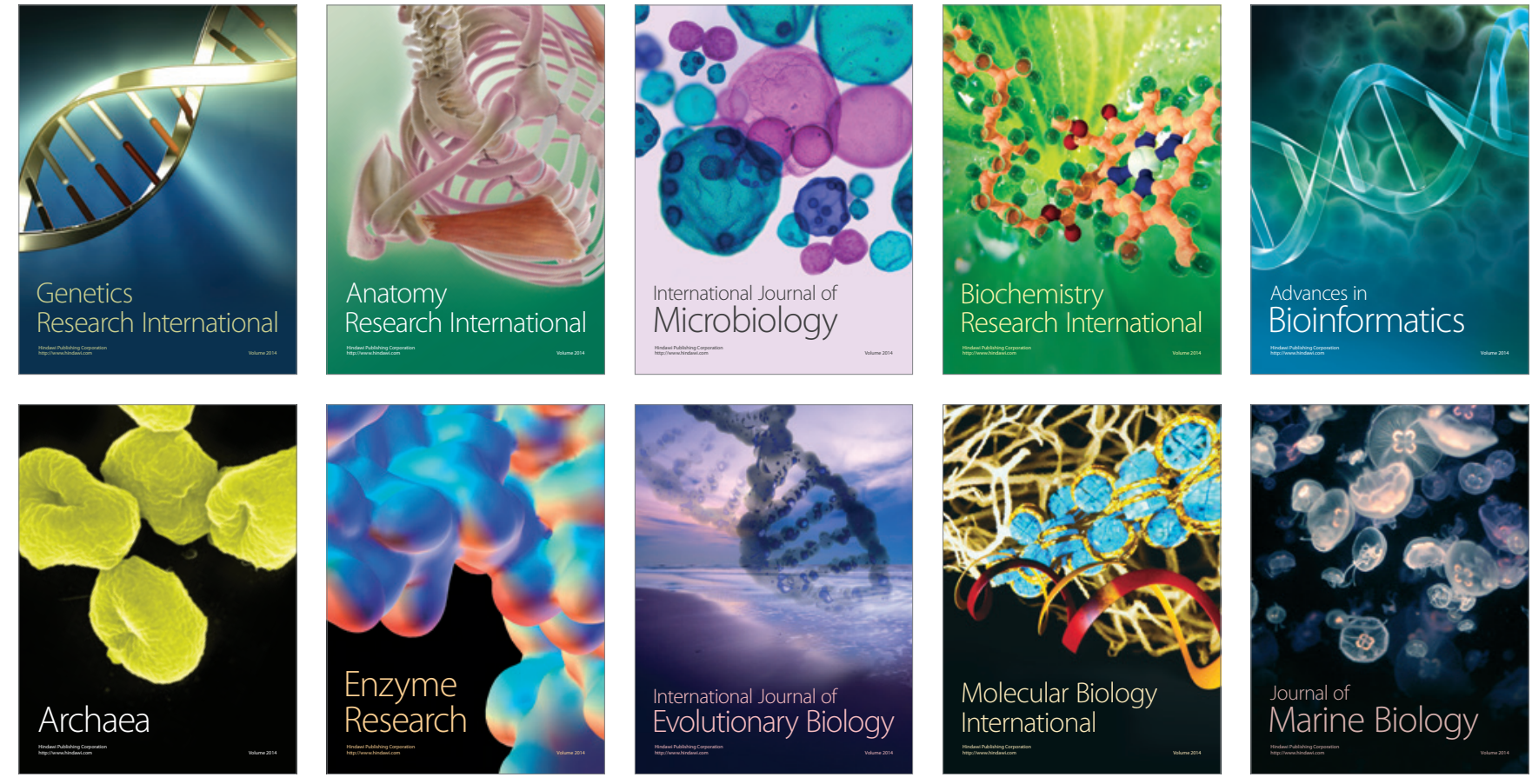